\title{
Effects of selective imidazolin-1 receptor agonists' vs Dihydropyridine calcium channel blockers on insulin resistance in patients of hypertension with metabolic syndrome: a meta-analysis of randomized controlled trials
}

\author{
Sharanabasayyaswamy B. Hiremath*, Priya Gandigawad
}

Department of Pharmacology, SDM Medical College, Dharwad, Karnataka, India

Received: 31 December 2015

Revised: 03 February 2016

Accepted: 04 February 2016

*Correspondence to:

Dr. Sharanabasayyaswamy B. Hiremath,

Email: dr.sharan83@yahoo.com

Copyright: (C) the author(s), publisher and licensee Medip Academy. This is an openaccess article distributed under the terms of the Creative Commons Attribution NonCommercial License, which permits unrestricted noncommercial use, distribution, and reproduction in any medium, provided the original work is properly cited.

\begin{abstract}
Background: Co-existence of insulin resistance in pre-diabetic hypertensive patients is associated with the higher risk for onset of diabetes and higher incidences of cardiovascular events in existing diabetics. Hence there is a need for selecting an anti-hypertensive drug with favourable metabolic effects. Present study aims at comparing the metabolic and hemodynamic effects of selective imidazolin-1 (I1) receptor agonists vs dihydropyridines (DHPs).

Methods: After electronic data base search in PUBMED, Cochrane library and EMBASE, total four RCTs were found eligible and included in analysis. Two studies used moxonidine $(0.2-0.4 \mathrm{mg})$, other two used rilmenidine $(1-2 \mathrm{mg})$ as selective I1-agonists and among DHPs, amlodipine $(5-10 \mathrm{mg})$ was used in three studies and isradipine $(5-10 \mathrm{mg})$ in one.

Results: Use of DHPs was associated with significant decrease in DBP (MD = $2.37 \mathrm{~mm} \mathrm{Hg} ; 95 \% \mathrm{CI}:-1.39,-3.36$ ) both at the end of short-term (3 months) and long-term (6 months) treatment. Significant decrease in fasting serum insulin level $(\mathrm{MD}=-2.63 \mathrm{mU} / \mathrm{L} ; 95 \% \mathrm{CI}:-4.66,-0.60)$ and HOMA index for insulin resistance ( $\mathrm{MD}=-1.14,95 \% \mathrm{CI}:-1.48,-0.80$ ) observed in patients treated with I1-agonists at three months were not persistent at the end of six months. Effects of both groups of drugs on plasma lipids concentration were inconclusive.

Conclusions: In addition to the concern over safety of I-1 agonists in heart failure patients, there is a lack of data on therapeutic benefits of I1-agonists on cardiovascular related events in hypertension. Hence for time being and with available evidences, DHPs seem to be better choice than I1-agonists in hypertensive patients with metabolic syndrome.
\end{abstract}

Keywords: I1 receptor agonists, Dihydropyridines, Insulin resistance, Hypertension

\section{INTRODUCTION}

Insulin resistance syndrome or metabolic syndrome is characterized by central obesity, hyperglycemia, hypertension, dyslipidemia and hyperinsulinemia. ${ }^{1,2} \mathrm{Co}$ existence of metabolic syndrome and hypertension is associated with the higher risk for development of type-2 DM in pre-diabetic patients. In established diabetics there is a risk of premature mortality and high incidences of cardiovascular events like myocardial infarction, stroke, etc. ${ }^{1,2}$ Central or visceral obesity plays a pivotal role in inducing the state of insulin resistance and thus ultimately the sequences of complications that follow due to development of hyperinsulinemia. ${ }^{2}$ Hyperinsulinemia is responsible for sodium retention, sympathetic nervous system stimulation, vascular smooth muscle hypertrophy and oxidative stress. ${ }^{3,4}$ Hence insulin resistance not only represents the mechanism or basis for development of type-2 DM but it is also the basis even for development of hypertension in type-2 DM patients and oxidative stress induced low grade systemic inflammation. What is alarming is its onset at the early age with adolescent population becoming susceptible to obesity and thus metabolic syndrome. ${ }^{5}$

With regard to treating hypertension in patients of metabolic syndrome, selection of an anti-hypertensive drug with favourable metabolic effects is theoretically relevant especially in pre-diabetic patients in order to prevent them from becoming overt diabetics. However as 
observed in 'ALLHAT' study patients of type-2 DM may not get benefit of reduction in cardiovascular events by using an anti-hypertensive drug with favourable metabolic effects unless they reduce blood pressure to target level. ${ }^{6,7}$ The favouritism towards use of ACEinhibitors (ACE-Is) or Angiotensin Receptor Blockers (ARBs) as first choice drugs in pre-diabetic and diabetic patients were shattered by this study and its results were difficult to be accepted. Naturally this study got criticism for various aspects but its long duration and inclusion of largest population in analysis made it to gain reliability and appreciation. ${ }^{7}$ Some of the subsequently conducted large clinical trials, meta-analysis, reviews still justified use of ACE-Is or ARBs as first choice anti-hypertensive drugs especially in elderly, in obese, in pre-diabetics and also supported their superiority with regard to lower incidence of end-stage kidney disease and cardiovascular risks in type- 2 DM patients. ${ }^{8-12}$ So the preferred drug to be used for hypertensive patients with metabolic syndrome who are prone for new onset diabetes or those with established type-2 DM perhaps continues to be ACE-Is or ARBs.

Need for search of another drug with favourable metabolic effects is relevant for two reasons. First, hypertensive patients with metabolic syndrome may need add on drug in addition to ACE-Is or ARBs under the circumstances where target level blood pressure is not achieved and it preferably needs addition of a class of drug with favourable metabolic effects. Second, this preferable drug should have the added benefits like ACEIs or ARBs without major adverse effects or risks like hyperkalemia and acute kidney injury seen with ACE-Is or ARBs. Second line drugs found with either beneficial or neutral metabolic effect are third generation nonselective beta-blocker carvedilol, alpha-1 blocker doxazosin, dihydropyridine calcium channel blockers (DHPs) and selective imidazolin-1 (I1) receptor agonists. ${ }^{13-15}$ Major drawback of using alpha-1 blockers as anti-hypertensive drug in patients of primary hypertension were evident in terms of increased incidences of heart failure in 'ALLHAT' study and these drugs are obviously not preferred as add-on drug. Hence the best second line anti-hypertensive drug to be added in the background of insulin resistance needs selection from either DHPs or carvedilol or I1- agonists. We did not have sufficient data to compare carvedilol with other two classes of drugs. Hence, present study aims at analyzing and comparing the effects of I1-agonists vs DHPs on blood pressure, indicators of insulin resistance and plasma lipids concentration.

\section{METHODS}

\section{Literature search methodology}

Two authors independently conducted electronic database search in PUBMED, Cochrane library and EMBASE for the randomized trials or cross-over trials. Two separate searches were conducted using search terms
"Moxonidine" AND "Hypertension" and "Rilmenidine" AND "Hypertension". Limits applied for the search in PUBMED were "randomized controlled studies", and "humans" while the limits applied for search in EMBASE were "randomized controlled trial" "conference paper" "article" "article in press" "embase" and "humans". No limits were applied in Cochrane library search. Search was limited to studies published up to $30^{\text {th }}$ July 2015 with no language restriction applied.

\section{Eligibility criteria}

Either cross-over studies or randomized trials with headto-head comparison of I1-agonists with DHPs in patients of either sex aged $>18$ yrs with primary hypertension and features of metabolic syndrome were eligible for inclusion. Studies with results of short duration of treatment ( $<1$ month) or those conducted in patients with complication like myocardial infarction or heart failure or those with incomplete data required for statistical analysis or those published as abstracts were considered under exclusion criteria.

\section{Data extraction and synthesis}

Two authors independently extracted baseline demographic, clinical data and other required data in data extraction sheet. Final data was prepared after reaching consensus between the two authors with regard to any discrepancies in data extracted. Indicators of insulin resistance like fasting serum insulin levels, fasting plasma glucose levels, Homeostatic Model Assessment (HOMA) index were collected. Changes in systolic and diastolic blood pressure, changes in plasma lipid concentrations were extracted.

\section{Outcome measures}

Primary outcome measures were mean differences in indicators of insulin resistance and secondary outcome measures were differences in blood pressure and plasma lipids concentrations between selective I1-agonists $v s$ DHPs. Though statistically inappropriate, subgroup analysis of "baseline" vs "study end point" values in I1agonists treated group and DHPs treated group was separately conducted to analyse the effect of the two classes of drugs from the baseline levels on all the outcome measures.

\section{Statistical methods}

Effects on outcome measures between two groups were assessed by calculating the mean difference (MD). Inverse variance method and both fixed and random effect models were used in analysis. Sensitivity analysis was conducted by comparing results of fixed effect model and random effects model. Heterogeneity between the studies was analysed by using Cochrane $Q$ test for heterogeneity and $\mathrm{I}^{2}$ test. A chi square test with $\mathrm{P}$ value $<0.10$ and $\mathrm{I}^{2}$ test value of $>50 \%$ was considered as 
indicator of significant heterogeneity. Funnel plot method was used for assessment of publication bias. Statistical analysis was conducted by using RevMan software version 5.3 .

\section{Quality evaluation}

Un-blinded quality assessment of published data of eligible studies was done independently by two authors as described by Nancy, et al. ${ }^{16}$ Final scores for the individual studies were allotted after arriving at consensus between the authors.

\section{RESULTS}

\section{Data search results}

Figure 1 shows the results of data search and the attrition diagram with number of studies excluded and reasons for exclusion. Excluded studies did not involve those articles published in language other than English. All the four RCTs comparing I1-agonists vs DHPs were eligible and included in the analysis. ${ }^{17-20}$ Of the four studies, two studies were on moxonidine and other two were on rilmenidine as I1-agonists and among the DHPs, amlodipine was used in three studies and is radipine in one study.

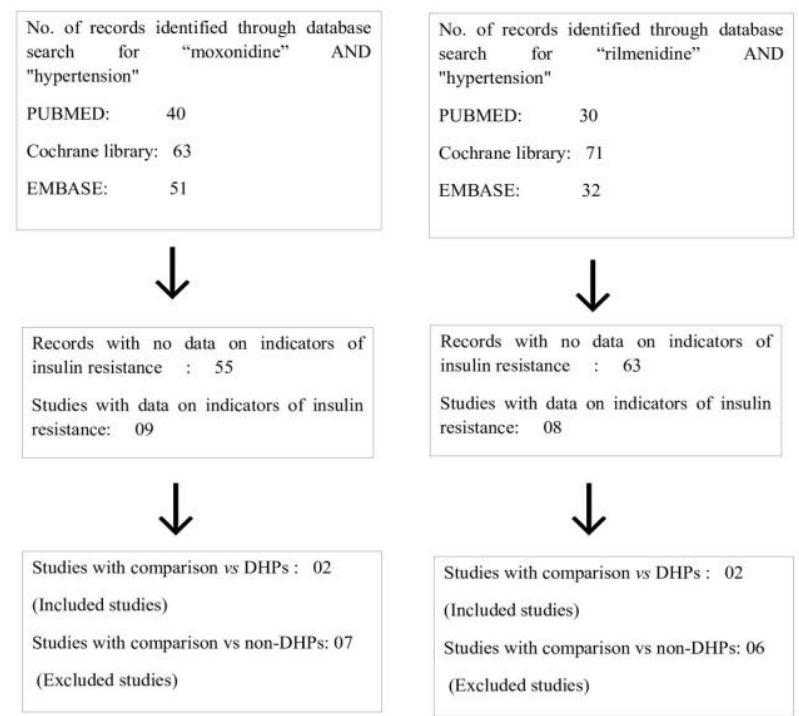

Figure 1: Literature search result and attrition diagram.

Table 1: Baseline demographic and clinical feature of patients included in eligible studies.

\begin{tabular}{|c|c|c|c|c|c|c|c|}
\hline \multirow[t]{2}{*}{ Factors } & \multirow{2}{*}{$\begin{array}{l}\text { Masajtis } 2010 \\
\text { M\&A group } \\
\text { (crossover) } \\
{[\mathrm{N}=15]}\end{array}$} & \multicolumn{2}{|c|}{ Sanjuliani 2006} & \multicolumn{2}{|c|}{ De luca 2000} & \multicolumn{2}{|c|}{ Widimsky 2006} \\
\hline & & $\begin{array}{l}\text { M-group } \\
{[\mathrm{N}=19]}\end{array}$ & $\begin{array}{l}\text { A-group } \\
{[\mathrm{N}=21]}\end{array}$ & $\begin{array}{l}\text { R-group } \\
{[\mathrm{N}=25]}\end{array}$ & $\begin{array}{l}\text { A-group } \\
{[\mathrm{N}=27]}\end{array}$ & $\begin{array}{l}\text { R-group } \\
{[N=45]}\end{array}$ & $\begin{array}{l}\text { I-group } \\
{[\mathrm{N}=48]}\end{array}$ \\
\hline Age (Yrs) & $48.3 \pm 14.3$ & $48.7 \pm 2.1$ & $46.5 \pm 1.8$ & $50.8 \pm 9.1$ & $53.3 \pm 8.5$ & $53 \pm 8.2$ & $56 \pm 8.9$ \\
\hline Sex ratio(M:F) & N/A & $4: 15$ & $3: 18$ & $10: 15$ & $18: 9$ & $29: 16$ & $22: 26$ \\
\hline BMI & $28.4 \pm 6.2$ & $35.4 \pm 1.7$ & $35.9 \pm 1.4$ & $31.3 \pm 2.0$ & $31.8 \pm 3.2$ & $34.3 \pm 4.0$ & $34.5 \pm 5.2$ \\
\hline Waist:hip ratio & N/A & $0.95 \pm 0.02$ & $0.92 \pm 0.02$ & $1.01 \pm 0.01$ & $1.01 \pm 0.02$ & $0.98 \pm 0.08$ & $0.96 \pm 0.08$ \\
\hline SBP $(\mathrm{mmHg})$ & $146.3 \pm 14.9$ & $160.4 \pm 2.4$ & $158.1 \pm 3.1$ & $151.8 \pm 11.8$ & $154.1 \pm 11.4$ & $152 \pm 12.2$ & $153 \pm 11.8$ \\
\hline $\mathrm{DBP}(\mathrm{mmHg})$ & $89.8 \pm 13.7$ & $102.4 \pm 1.3$ & $104.2 \pm 1.3$ & $98.5 \pm 4.1$ & $98.5 \pm 3.6$ & $94 \pm 8.4$ & $94 \pm 5.3$ \\
\hline FPG (mmol/l) & $6.2 \pm 1.6$ & $5.5 \pm 0.18$ & $5.5 \pm 0.14$ & $5.51 \pm 1.06$ & $5.29 \pm 1.37$ & $6.4 \pm 1.1$ & $6.6 \pm 0.8$ \\
\hline FSI (mU/l) & $17 \pm 7.3$ & $29.9 \pm 5.7$ & $23.5 \pm 2.3$ & $68.8 \pm 49.3$ & $63.5 \pm 42.8$ & $14.0 \pm 9.4$ & $16.0 \pm 7.7$ \\
\hline HOMA & $4.5 \pm 2.0$ & $7.2 \pm 1.9$ & $5.5 \pm 0.6$ & N/A & N/A & $4.2 \pm 3.0$ & $4.8 \pm 2.5$ \\
\hline $\mathrm{TC}(\mathrm{mmol} / \mathrm{l})$ & $5.3 \pm 1.24$ & $5.83 \pm 0.32$ & $5.69 \pm 0.22$ & $5.23 \pm 0.63$ & $5.56 \pm 0.74$ & $5.9 \pm 1.2$ & $5.8 \pm 1.0$ \\
\hline $\begin{array}{l}\text { Triglycerides } \\
(\mathrm{mmol} / \mathrm{l})\end{array}$ & $4.27 \pm 1.69$ & $4.53 \pm 0.55$ & $3.97 \pm 0.41$ & $2.5 \pm 0.49$ & $2.34 \pm 0.36$ & $2.7 \pm 1.5$ & $2.5 \pm 1.3$ \\
\hline HDL-C (mmol/l) & $1.3 \pm 0.29$ & $1.22 \pm 0.08$ & $1.13 \pm 0.06$ & $1.24 \pm 0.15$ & $1.16 \pm 0.22$ & $1.3 \pm 0.2$ & $1.3 \pm 0.3$ \\
\hline LDL-C (mmol/l) & $3.49 \pm 1.01$ & $3.75 \pm 0.32$ & $3.71 \pm 0.41$ & $3.26 \pm 0.62$ & $3.33 \pm 0.7$ & $3.5 \pm 1.0$ & $3.5 \pm 0.7$ \\
\hline
\end{tabular}

All Values are in Mean \pm SD, A: Amlodipine, M: Moxonidine, R: Rilmenidine, N/A: Not Available, HOMA: Homeostasis model assessment, TC: Total Cholesterol

\section{Characters of included studies}

Table 1 and 2 show the baseline demographic, clinical features and characteristics of individual studies included in the analysis. Differences in the baseline demographic and clinical features between the two comparator groups in all the four studies were statistically insignificant. Except for in the study by Sanjuliani, et al which included type-2 DM patients, other three studies included pre-diabetic patients with metabolic syndrome. Excluding the similarity in the doses of drugs used, all the studies varied significantly with regards to use of concomittent medications and in duration of follow up. In study by Masajtis, et al use of other antihypertensive medication including ACE-Is, ARBs, diuretics, alpha and beta blockers was allowed and in study by De Luca, et al none 
were allowed. ${ }^{17,19}$ Considering the cross-over design of study by Masajtis, et al this variation might not be responsible for intra-study heterogeneity but perhaps would lead to significant inter-study heterogeneity.
Quality score achieved by all studies except by Sanjuliani, et al was more than $75 \%$. There was evidence of significant publication bias with most of the effect size measures estimated by random effect model.

Table 2: Characteristics \& quality scores of individual studies.

\begin{tabular}{|c|c|c|c|c|}
\hline Study & Masajtis 2010 & Sanjuliani 2006 & De luca 2000 & Widimsky 2006 \\
\hline Study design \& duration & Cross-over 2 months & $\begin{array}{l}\text { Randomized } \\
\text { Open label } \\
6 \text { months }\end{array}$ & $\begin{array}{l}\text { Randomized } \\
\text { Double blind } \\
4 \text { months }\end{array}$ & $\begin{array}{l}\text { Randomized } \\
\text { Double blind } \\
6 \text { months }\end{array}$ \\
\hline Centres \& country & Single centre Poland & $\begin{array}{l}\text { Single centre } \\
\text { Brazil }\end{array}$ & $\begin{array}{l}\text { Single centre } \\
\text { Italy }\end{array}$ & $\begin{array}{l}\text { Multi centre } \\
\text { Czech Republic } \\
\text { Slovak Republic }\end{array}$ \\
\hline Co-morbidity & Insulin resistance & Obesity & $\begin{array}{l}\text { Metabolic } \\
\text { Syndrome }\end{array}$ & $\begin{array}{l}\text { Metabolic } \\
\text { Syndrome }\end{array}$ \\
\hline Intervention & $\begin{array}{l}\text { M: } 0.4 \mathrm{mg} / \mathrm{d} \\
\text { A: } 10 \mathrm{mg} / \mathrm{d}\end{array}$ & $\begin{array}{l}\text { M:0.2-0.4mg/d } \\
\text { A: } 5-10 \mathrm{mg} / \mathrm{d}\end{array}$ & $\begin{array}{l}\mathrm{R}: 1-2 \mathrm{mg} / \mathrm{d} \\
\mathrm{A}: 5-10 \mathrm{mg} / \mathrm{d}\end{array}$ & $\begin{array}{l}\mathrm{R}: 1-2 \mathrm{mg} / \mathrm{d} \\
\mathrm{I}: 5-10 \mathrm{mg} / \mathrm{d}\end{array}$ \\
\hline Other interventions & Anti-HTs* & N/A & None allowed & Indapamide $* *$ \\
\hline Quality score & $78 \%$ & $65 \%$ & $81 \%$ & $76 \%$ \\
\hline
\end{tabular}

* Antihypertensive used: ACE-Is (11 patients), ARBs, (7 patients), loop diuretics (10 patients) thiazides diuretics (5 patients), betablockers (13 patients) and alpha-blockers (4 patients).

** For patients with uncontrolled hypertension indapamide SR $1.5 \mathrm{mg}$ once daily was used

Table 3: Effect size measures of all outcome measures.

\begin{tabular}{|c|c|c|c|c|}
\hline Outcome measures & $\begin{array}{l}\text { Mean difference ( } \approx 3 \mathrm{mths} \text { ) } \\
\text { (Random effect model) }\end{array}$ & $\mathbf{N}$ & $\begin{array}{l}\text { Mean Difference (6mths) } \\
\text { (random effect model) }\end{array}$ & $\mathbf{N}$ \\
\hline FSI (mIU/L): & $2.29[-1.76,6.34]$ & 170 & $1.60[-10.39,13.59]$ & 126 \\
\hline I1-agonists: & $-2.53[-4.60,-0.46]^{*}$ & 183 & $-0.84[-2.28,0.60]$ & 130 \\
\hline DHPs : I1-agonists vs DHPs: & $-2.63[-4.66,-0.60]^{*}$ & 174 & $-1.22[-2.61,0.17]$ & 128 \\
\hline FPG (mg/dl): & $-5.09[-8.68,-1.49]^{*}$ & 170 & $-2.87[-5.33,-0.41]^{*}$ & 126 \\
\hline I1-agonists: & $-0.07[-1.94,1.80]$ & 183 & $1.67[-7.97,11.30]$ & 130 \\
\hline DHPs : I1-agonists vs DHPs: & $4.61[-0.71,9.92]$ & 174 & $2.73[-3.46,8.93]$ & 128 \\
\hline HOMA index: & $0.30[-0.17,0.78]$ & 200 & $0.10[-3.13,3.34]$ & 126 \\
\hline I1-agonists: & $-0.69[-1.47,0.09]$ & 213 & $-0.67[-1.07,-0.27]^{*}$ & 130 \\
\hline DHPs: I1-agonists vs DHPs & $-1.14[-1.48,-0.80]^{*}$ & 204 & $-0.38[-0.80,0.05]$ & 128 \\
\hline SBP (mm Hg): & $15.40[9.09,21.72]^{*}$ & 170 & $17.63[15.02,20.23]^{*}$ & 122 \\
\hline I1-agonists: & $17.66[13.35,21.97]^{*}$ & 180 & $20.26[12.54,27.98]^{*}$ & 126 \\
\hline DHPs: I1-agonists vs DHPs: & $2.68[1.27,4.09]^{*}$ & 175 & $4.34[-3.36,12.04]$ & 124 \\
\hline DBP $(\mathrm{mm} \mathrm{Hg})$ : & $10.45[7.59,13.32]^{*}$ & 170 & $11.25[7.71,14.79]^{*}$ & 122 \\
\hline I1-agonists: & $12.71[9.05,16.37]^{*}$ & 180 & $12.61[5.85,19.36]^{*}$ & 126 \\
\hline DHPs: I1-agonists vs DHPs: & $2.37[1.39,3.36]^{*}$ & 175 & $1.32[0.51,2.14]^{*}$ & 124 \\
\hline T. Chol. (mg/ dl): & $-3.81[-10.64,3.02]$ & 156 & $-4.43[-24.33,15.47]$ & 126 \\
\hline I1-agonists: & $-1.92[-7.40,3.56]$ & 160 & $-3.35[-8.66,1.97]$ & 130 \\
\hline DHPs: I1-agonists vs DHPs: & $7.33[1.08,13.58]^{*}$ & 158 & $5.50[-16.26,27.25]$ & 128 \\
\hline HDL-C (mg/ dl): & $0.89[-2.66,4.44]$ & 156 & $1.12[-3.50,5.74]$ & 126 \\
\hline I1-agonists: & $2.74[1.27,4.22]^{*}$ & 160 & $-1.72[-3.22,-0.22]^{*}$ & 130 \\
\hline DHPs: I1-agonists vs DHPs: & $2.64[-3.06,8.35]$ & 158 & $-0.22[-6.51,6.07]$ & 128 \\
\hline LDL-C (mg/ dl): & $-5.56[-12.08,0.96]$ & 142 & $-6.37[-22.64,9.90]$ & 112 \\
\hline I1-agonists: & $-2.30[-9.03,4.43]$ & 158 & $-7.52[-20.44,5.40]$ & 128 \\
\hline DHPs: I1-agonists vs DHPs: & $2.38[-5.55,10.31]$ & 150 & $0.58[-4.85,6.01]$ & 120 \\
\hline TGs (mg/dl): & $17.35[6.06,28.63]^{*}$ & 156 & $15.10[2.30,27.90]^{*}$ & 126 \\
\hline I1-agonists: & $-7.87[-17.02,1.28]$ & 130 & $7.32[-2.42,17.06]$ & 130 \\
\hline DHPs: I1-agonists vs DHPs: & $-4.96[-14.25,4.33]$ & 128 & $13.40[3.24,23.55]^{*}$ & 128 \\
\hline
\end{tabular}

* Significant difference, All Values are Mean \pm SD, T. Chol: Total Cholesterol, TGs: Triglycerides 


\section{Outcome measures}

Considering the possibility of significant inter-study heterogenity, we present the results of random effects model as representatives of true effects. Table 3 shows the effects size measures at short term $(\approx 3$ months $)$ and long-term ( $\approx 6$ months) study period of individual groups of drug and between their baseline values vs study end point values.

\section{Effect on fasting serum insulin}

Significant observations after short term treatment were decrease in serum fasting insulin levels from baseline (vs study end point) values in I1-agonists treated group by $19.74 \mathrm{mU} / 1$, increase in serum fasting insulin levels from baseline (vs end of study) values in DHPs treated group by $2.53 \mathrm{mU} / \mathrm{l}$ and decrease in fasting serum insulin level in group treated by I1-agonists (vs DHPs) by $-2.63 \mathrm{mU} / 1$. At the end of six months treatment all these significant observations were absent.

\section{Effect on fasting plasma glucose}

The only significant change after short term treatment was increase in the level of fasting plasma glucose level from baseline (vs study end point) values in I1-agonists treated group by $5.09 \mathrm{mg} / \mathrm{dl}$. This observation persisted even at the end of six months treatment but the amount of increase was slightly less $(2.87 \mathrm{mg} / \mathrm{dl})$.

\section{Effect on HOMA index}

At the end of short term treatment, there was significant decrease in HOMA index in group treated by I1-agonists (vs DHPs) by -1.14 (Figure 2). But at the end of six months above significances were not persistent but instead there was significant increase in HOMA index by 0.67 from baseline (vs study end point) in DHPs treated group.

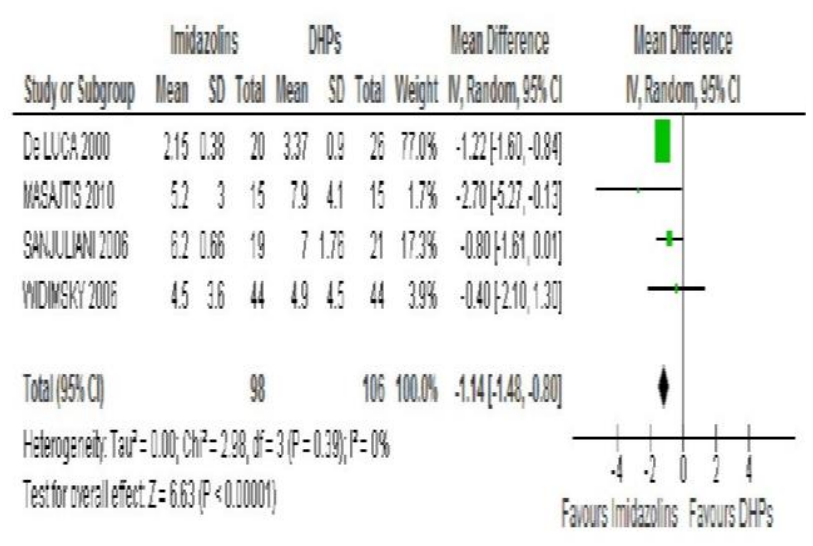

Figure 2: Forest plot showing mean difference in HOMA index at 3 months.

\section{Effect on SBP}

After short term treatment, both the I1-agonists and DHPs treated group showed significant decrease in the SBP from baseline by $-15.40 \mathrm{~mm} \mathrm{Hg}$ and $-17.66 \mathrm{~mm} \mathrm{Hg}$ respectively. The difference in amount of decrease was lesser in I1-agonists (vs DHPs) by $2.68 \mathrm{~mm} \mathrm{Hg}$ (Figure 3 ). However at the end of six months, there was slightly higher amount of decrease in SBP in I1-agonists treated group from baseline by $-17.63 \mathrm{~mm} \mathrm{Hg}$. Hence there was insignificant difference in the amount of decrease in SBP between I1-agonists vs DHPs at six months.

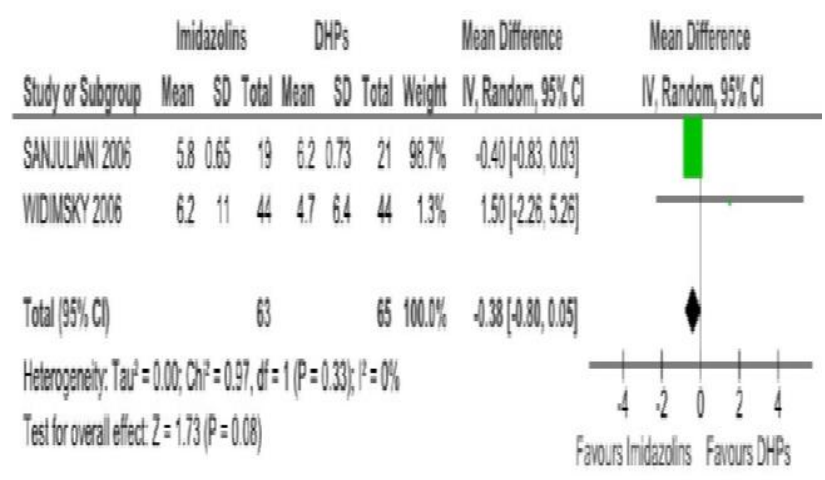

Figure 3: Forest plot showing mean difference in SBP at 3 months.

\section{Effect on DBP}

At the end of short term treatment, amount of decrease in DBP from baseline values in I1-agonists and DHPs treated groups were $-10.45 \mathrm{~mm} \mathrm{Hg}$ and $-12.71 \mathrm{~mm} \mathrm{Hg}$ respectively. The difference in amount of decrease was lesser by $2.37 \mathrm{~mm} \mathrm{Hg}$ in I1-agonists (vs DHPs). At the end of six months, slightly higher amount of decrease in DBP was observed in I1-agonists (vs baseline) by $11.25 \mathrm{~mm} \mathrm{Hg}$ and it was unchanged in DHPs (vs baseline). Hence the difference in amount of decrease in DBP by I1-agonists (vs DHPs) at six months was slightly lesser by $1.32 \mathrm{~mm} \mathrm{Hg}$.

\section{Effects on total cholesterol concentrations}

Only significant observation at the end of short term treatment was an increase in the level of total cholesterol in group treated by DHPs (vs I1-agonists) by $7.33 \mathrm{mg}$. However this significance was absent at the end of six months.

\section{Effects on HDL cholesterol concentrations}

After short term treatment, only significant observation was increase in the level of HDL cholesterol (vs baseline) values in DHPs treated group by $2.74 \mathrm{mg} / \mathrm{dl}$. Quite interestingly, this benefit was reversed at the end of six months treatment where in the level of HDL decreased by $1.72 \mathrm{mg} / \mathrm{dl}$. 


\section{Effects on triglyceride concentrations}

At short term treatment, there was decrease in the level of triglycerides from baseline values in I1-agonists treated group by $-17.35 \mathrm{mg} / \mathrm{dl}$. Quite interestingly, at the end of six months treatment, there was significant decrease in the level of triglycerides in group treated by I1-agonists (vs DHPs) by $-13.40 \mathrm{mg} / \mathrm{dl}$ despite decrease in the level of triglycerides from baseline (vs study end point) values in I1-agonists treated group by $-15 \mathrm{mg} / \mathrm{dl}$.

At the end of 3 months, no significant differences were observed either within I1-agonists treated group or DHPs treated group or between I1-agonists vs DHPs treated groups with regard to changes in LDL cholesterol levels. There was significant heterogeneity observed with regards to effects of both I1-agonists and DHPs on the amount of decrease in SBP and DBP from their baseline values but not in the level of decrease by DHPs vs I1agonists. Like the short term treatment effects, all the measured effects were robust as the values correlated well with the effect size measures of fixed effect model. There was significant inter-study heterogeneity observed with regards to the amount of decrease in SBP by DHPs and amount of decrease in DBP by I1-agonists and DHPs, as well as even in the difference observed between I1agonists vs DHPs. Sufficient data were not available to analyse the effects of individual groups of drugs on the other factors like body weight, waist-hip ratio and heart rate.

\section{DISCUSSION}

Overview of the results of the study give impressions that the major benefits of I1-agonists is their favourable effects on indicators of insulin resistance and that of DHPs is blood pressure lowering effect. Considering the importance of achieving the target blood pressure level, it is obvious that despite the favourable effect of I1-agonists on insulin resistance the blood pressure lowering efficacy of DHPs is perhaps of much more significance. Moreover, as observed in our study the benefits of I1agonists on insulin resistance could not persist at six months. But persistent effect of DHPs on DBP even at the end of six moths favours DHPs over I1-agonists. However, there was lack of difference in the amount of decrease in SBP between I1-agonists $v s$ DHPs at six months. I1-agonists have additional beneficial effect of inhibiting sympathetic over activity and thus inhibition of vascular smooth muscles hypertrophic remodelling. ${ }^{21,22}$ DHPs though do not have any inhibitory effect on sympathetic over activity, they are shown to possess antiinflammatory action and thus inhibitory action on vascular smooth muscle remodeling. ${ }^{23,24}$

Whatever the differences in the mechanisms and effects between these two classes of drugs, what is important is their extrapolation into therapeutic benefits. With regard to therapeutic benefits, in 'ALLHAT' study it was found that use of amlodipine was associated with higher risk of cardiac failure at six years. In another study, amlodipine was not superior to placebo with regard to survival benefits in patients with heart failure. ${ }^{25}$ There are no such large and or long term studies analysing risks and benefits of I1-agonists in patients of primary hypertension on cardiovascular related events. However, I1-agonists were a big failure in patients with heart failure as there was very high incidence of mortality compared to placebo in 'MOXCON' trial of moxonidine. ${ }^{26}$ Whether use of I1-agonists is associated with higher risk of heart failure in patients with primary hypertension is uncertain but very high incidence of mortality rate in patients of heart failure by moxonidine has unfortunately become a major drawback in using these drugs even for primary hypertension.

There are two contradictory effects observed with regard to the effects of I1-agonists on indicators of insulin resistance. There was an increase in fasting plasma glucose associated with decrease in fasting serum insulin level in I1-agonists treated group. This contradiction could be partly explained on the basis of alpha- $2 b$ receptor mediated direct inhibition of insulin secretion from beta cells of pancreas by I1-agonists. ${ }^{27,28}$ Hence whether I1-agonists actually decrease insulin resistance by increasing tissue sensitivity to insulin is doubtful and questionable. But it may have negative impression about I1-agonists while making a decision on selecting I1agonists over DHPs. The decision on to which group is better is further complicated by mixed and inconsistent effects of I1-agonists and DHPs on plasma lipids concentration. Since the free fatty acids are known to play important role in development of insulin resistance as well as type-2 DM, the actual effects of these two groups of drugs due to their effect of alteration in lipid level needs to be further analyzed..$^{29,30}$

\section{CONCLUSION}

To conclude, it is uncertain that long term use of DHPs may be associated with favourable effects on insulin resistance. Likewise, the I1-agonists may not have beneficial effects on plasma lipid levels. Comparatively better and consistent DBP lowering effects of DHPs may favour them over I1-agonists. In addition to the concern over safety of I-1 agonists in heart failure patients, there is a lack of long term study data on therapeutic benefits of I1-agonists on cardiovascular related mortality or morbidity in primary hypertension. Hence for time being and with available evidences, DHPs seem to be better choice than I1-agonists in hypertensive patients with metabolic syndrome. Though safety analysis was not the objectives of our study, both classes of drugs were found to be reasonably safe without any serious adverse drug reactions in all the four eligible studies included in the analysis. Major limitations of our study were inclusion of few studies with small sample size, significant publication bias and heterogeneity between the studies. Hence the results have to be interpreted cautiously. 
Funding: No funding sources

Conflict of interest: None declared

Ethical approval: The study was approved by the Institutional Ethics Committee

\section{REFERENCES}

1. Zhou MS, Wang A, Yu H. Link between insulin resistance and hypertension: what is the evidence from evolutionary biology? Diabetology \& Metabolic Syndrome. 2014;6(12):1-8.

2. Rizos CV, Elisaf MS. Antihypertensive drugs and glucose metabolism. World $\mathrm{J}$ Cardiol. 2014;6(7):517-30.

3. Abel ED, O'shea KM, Ramasamy R. Insulin resistance: metabolic mechanisms and consequences in the heart. Arterioscler Thromb Vasc Biol. 2012;32:2068-76.

4. Jia G, Aroor AR, Demarco VG, Martinez-Lemus LA, Meininger GA, Sowers JR. Vascular stiffness in insulin resistance and obesity. Front. Physiol. 2015;6:(231):1-8.

5. Steinberger J, Daniels SR. Obesity, insulin resistance, diabetes, and cardiovascular risk in children. Circulation. 2003;107:1448-53.

6. Furberg CD, Wright JT, Davis BR, Cuttler JA, Alderman M, Black H. Major outcomes in high-risk hypertensive patients randomized to angiotensinconverting enzyme inhibitor or calcium channel blocker vs diuretic: the antihypertensive and lipidlowering treatment to prevent heart attack trial (ALLHAT). JAMA. 2002;288(23):2981-97.

7. González-juanatey JR. After the ALLHAT trial, what do we know about treatment for hypertension that we did not know before?. Rev Esp Cardiol. 2003;56(7):642-8.

8. Dahlöf B, Devereux RB, Kjeldsen SE, Julius S, Beevers G, De Faire U. Cardiovascular morbidity and mortality in the losartan intervention for endpoint reduction in hypertension study (LIFE): A randomised trial against atenolol. Lancet. 2002;359(9311):995-1003.

9. Wing LM, Reid CM, Ryan P, Beilin LJ, Brown MA, Jennings GL. A comparison of outcomes with angiotensin-converting-enzyme inhibitors and diuretics for hypertension in the elderly. $\mathrm{N}$ Engl $\mathrm{J}$ Med. 2003;348:583-92.

10. Cooper-dehoff RM, Handberg EM, Mancia G, Zhou Q, Champion A, Legler UF. INVEST revisited: A review of findings from the international verapamil SR-trandolapril study (INVEST). Expert Rev Cardiovasc Ther. 2009;7(11):1329-40.

11. Palmer SC, Mavridis D, Navarese E, Craig JC, Tonelli M, Salanti G. Comparative efficacy and safety of blood pressure-lowering agents in adults with diabetes and kidney disease: a network metaanalysis. Lancet. 2015;385:2047-56.

12. Agodoa L, Baigent C, Black H, Boissel JP, Brenner B. Effects of different blood pressure-lowering regimens on major cardiovascular events in individuals with and without diabetes mellitus. Arch Intern Med. 2005;165:1410-9.

13. Schachter M. Metabolic effects of moxonidine and other centrally acting antihypertensives. Diabetes Obes Metab. 1999;1(6):317-22.

14. Torres YC, Katholi RE. Novel treatment approaches in hypertensive type 2 diabetic Patients. World J Diabetes. 2014;5(4):536-45.

15. Hansson L. Therapy of hypertension and metabolic syndrome: today's standard and tomorrow's perspectives. Blood Press suppl. 1998;3:20-2.

16. Nancy GB, Robert AP. Meta-analysis: neither quick nor easy. BMC medical research methodology. 2002;2:10.

17. Masajtis ZA, Majer J, Nowicki M. Effect of moxonidine and amlodipine on serum Ykl-40, plasma lipids and insulin sensitivity in Insulinresistant hypertensive patients - A randomized, crossover trial. Hypertension research. 2010;33:34853.

18. Sanjuliani AF, De Abreu VG, Francischetti EA. Selective imidazoline agonist moxonidine in obese hypertensive Patients. Int $\mathbf{J}$ Clin Pract. 2006;60(5):621-29.

19. De lucaa N, Iizzoa R, Fontanaa D, Iovinoa G, Argenzianoa L, Vecchioneb C. Haemodynamic and metabolic effects of rilmenidine in Hypertensive patients with metabolic syndrome X. A Doubleblind parallel study versus amlodipine. Journal of hypertension. 2000;18:1515-22.

20. Widimský JA, Sirotiaková J. Efficacy and tolerability of rilmenidine compared with is radipine in hypertensive patients with features of metabolic syndrome. Current Medical Research and Opinion. 2006;22:1287-94.

21. Regunathan S, Reis DJ. Stimulation of imidazoline receptors inhibits proliferation of human coronary artery vascular smooth muscle cells. Hypertension. 1997;30:295-300.

22. Regunathan S, Youngson C, Raasch W, Wang H, Reis DJ. Imidazoline receptors and agmatine in blood vessels: a novel system inhibiting vascular smooth muscle proliferation. J Pharmacol Exp Ther. 1996;276(3):1272-82.

23. Toba $H$, Nakagawa $Y$, Miki S, Shimizu T, Yoshimura A, Inoue R. Calcium channel blockades exhibit anti-inflammatory and antioxidative effects by augmentation of endothelial nitric oxide synthase and the inhibition of angiotensin converting enzyme in the $\mathrm{n}(\mathrm{g})$-nitro-l-arginine methyl ester-induced hypertensive rat aorta: vasoprotective effects beyond the blood pressure-lowering effects of amlodipine and manidipine. Hypertens Res. 2005;28(8):689700 .

24. Komoda $\mathrm{H}$, Inoue $\mathrm{T}$, Node $\mathrm{K}$. Anti-inflammatory properties of azelnidipine, a dihydropyridine-based calcium channel blocker. Clin Exp Hypertens. 2010;32(2):121-8.

25. Packer M, Carson P, Elkayam U, Konstam MA, Moe G, O'connor C. Effect of amlodipine on the 
survival of patients with severe chronic heart failure due to a nonischemic cardiomyopathy. JCHF. 2013;1(4):308-14.

26. Cohn JN, Pfeffer MA, Rouleau J, Sharpe N, Swedberg K, Straub M. Adverse mortality effect of central sympathetic inhibition with sustained-release moxonidine in patients with heart failure (MOXCON). Eur J Heart Fail. 2003;5(5):659-67.

27. Shannon HE, Lutz EA. Effects of the I (1) imidazoline/alpha (2)-adrenergic receptor agonist moxonidine in comparison with clonidine in the formalin test in rats. Pain. 2000;85(1-2):161-7.

28. Khan ZP, Ferguson CN, Jones RM. Alpha-2 and imidazoline receptor agonists their pharmacology and therapeutic role. Anaesthesia. 1999;54:146-65.
29. Bhattacharya S, Dey D, Sankar SR. J. Molecular mechanism of insulin resistance. Biosci. 2007;32(2):405-13.

30. Boden G. Role of fatty acids in the pathogenesis of insulin Resistance and NIDDM. Diabetes. 1996;45:3-10.

Cite this article as: Hiremath SB, Gandigawad P. Effects of selective imidazolin-1 receptor agonists' vs Dihydropyridine calcium channel blockers on insulin resistance in patients of hypertension with metabolic syndrome: a meta-analysis randomized controlled trials. Int J Basic Clin Pharmacol 2016;5:394-401. 